\title{
Commentary Wnt signaling in breast cancer: have we come full circle?
} Anthony MC Brown

Department of Cell Biology and Anatomy, Weill Medical College of Cornell University, and Strang Cancer Prevention Center, New York, USA

Correspondence: Strang Cancer Research Laboratory at The Rockefeller University, 1230 York Avenue, New York, NY 10021, USA. Tel: +1 212734 0567, ext 232; fax: +1 212472 9471; e-mail: amcbrown@med.cornell.edu

Received: 9 July 2001

Breast Cancer Res 2001, 3:351-355

Revisions requested: 27 July 2001

Revisions received: 10 August 2001

Accepted: 13 August 2001

Published: 6 September 2001

\author{
(C) 2001 BioMed Central Ltd \\ (Print ISSN 1465-5411; Online ISSN 1465-542X)
}

\begin{abstract}
Since the original identification of Wnt1 as a mammary oncogene in mouse mammary tumor virus infected mice, questions have been asked about its relevance to human breast cancer. Wnt1 is now known to be one of a large family of Wnt genes encoding structurally similar secreted signaling proteins, several of which are functionally redundant. The principal intracellular signaling pathway activated by these proteins has been elucidated in recent years. Components of this pathway include proto-oncogene products, such as $\beta$-catenin, and tumor suppressor proteins such as APC. Although WNT1 itself has not been implicated in human breast neoplasms, it has been reported that other WNT genes are sometimes overexpressed in human breast cancer and there is growing evidence that downstream components of the Wnt signaling pathway are activated in a significant proportion of breast tumors.
\end{abstract}

Keywords: APC, breast cancer, $\beta$-catenin, mouse mammary tumor virus, Wnt signaling

\section{Introduction}

The discovery of Wnt1 as a mammary oncogene in the early 1980s was, in one sense, the culmination of many years of research on mouse models of breast cancer [1,2]. The main causative agent of those tumors was the mouse mammary tumor virus (MMTV). Although no equivalent viral etiology has been demonstrated for breast cancer in humans, studies of the MMTV model were fueled by the expectation that the underlying molecular mechanisms of tumorigenesis would have similarities with those in human breast cancer. Has the Wnt1 paradigm fulfilled its promise in terms of relevance to the human disease? While the molecular genetic similarities between the murine and human breast cancers are not as simple as once envisioned, there is growing evidence that Wnt proteins and/or components of their signaling pathway may indeed be of widespread significance for human breast cancer.

\section{Wnt1 in mouse mammary tumors}

The early work of Nusse and Varmus showed that MMTV acts as an insertional mutagen in mouse mammary tissue and that, in many MMTV-induced tumors, integration of proviral DNA results in transcriptional activation of the gene we now know as Wnt1 [3]. The consequences of ectopic activation of Wnt1 in the mammary gland were subsequently recapitulated experimentally in transgenic mice. This confirmed the oncogenic potential of Wnt1 since the animals were predisposed to mammary tumors, albeit after a long latency $[3,4]$. Wnt1 expression was also sufficient to promote premature ductal branching and lobuloalveolar hyperplasia, a state of differentiation similar to that normally observed during pregnancy. Although surprising in the light of dogmas that inversely correlate cell proliferation with terminal differentiation, these data were consistent with prior evidence that MMTV-induced tumors

APC = adenomatous polyposis coli; GSK-3 $\beta=$ glycogen synthase kinase-3 $\beta$; Lef1 = lymphoid enhancer factor-1; LRP = low density lipoprotein receptor-related protein; MMTV = mouse mammary tumor virus; $\mathrm{Tcf}=\mathrm{T}$-cell factor. 
could arise from hyperplastic alveolar nodules [5]. The oncogenic potential of MMTV thus became largely explainable through the ability of the virus to activate Wnt1 or a handful of alternative proto-oncogenes [6].

\section{From mouse to human: no simple step}

If aberrant activation of Wnt 1 expression in the mouse can promote mammary tumors, what about human WNT1 in breast cancer? Once the human homolog was cloned, several laboratories asked whether WNT1 transcripts were detectable in human breast carcinomas. Although few of these data have been published, the answer appears to have been a resounding 'no' [7]. Assisted by the wisdom of hindsight, however, we can now see that the initial questions about WNT1 expression in human breast cancer were overly simplistic in at least two ways. First, there is a family of WNT genes, several of which may have the same consequences as Wnt1 if overexpressed in human cancer. Second, the real question should be a broader one: is there aberrant activation of the Wnt signaling pathway in human breast cancer, whether through ligand overexpression or mutation of downstream cellular components?

\section{Redundancy in the family}

Wnt1 encodes a cysteine-rich secreted glycoprotein that acts as an extracellular signaling factor. The gene belongs to a family of 19 Wnt genes that encode strikingly similar proteins, and these are now recognized as one of the most important families of signaling molecules that regulate development [8]. Wnt proteins influence a wide range of tissues and affect processes such as cell fate determination, cell growth, cell death, and differentiation. A variety of in vivo and cell culture assays have demonstrated functional redundancy among Wnt family members. For example, Wnt1 achieves the same effects as Wnt2, Wnt3a, Wnt4, Wnt7a, and Wnt7b in an in vitro nephrogenesis assay $[9,10]$, while the ability of Wnt1 to cause morphological transformation of the mammary cell line C57MG is shared by Wnt2, Wnt3, Wnt3a, Wnt7a, and Wnt11 [11,12]. Studies of MMTV have also pointed to redundancy in the oncogenic potential of Wnt genes in vivo: in tumors with lack activation of Wnt1, there can instead be insertional activation of Wnt3 or Wnt10b [12,13].

It is notable that several members of the Wnt gene family, unlike Wnt1 itself, are normally expressed in the developing mammary gland. These include Wnt2, Wnt4, Wnt5a, Wnt5b, Wnt6, Wnt7b, and Wnt10b [12]. The dynamic expression patterns of these Wnt genes during adolescence, pregnancy, and lactation strongly suggest that they function to regulate growth and differentiation of the gland $[14,15]$. This notion is supported by the delayed sidebranching of mammary ducts observed in the absence of Wnt4 and by the premature ductal branching and alveolar development that results from ectopic expression of Wnt1 or Wnt10b $[4,13,16]$.
Collectively, the data already presented support the idea that deregulated expression of any one of several WNT proteins in human breast tissue could potentially phenocopy some of the consequences of Wnt1 activation in mice. When the net is cast that wide, there is evidence consistent with this possibility in breast cancer. Although systematic studies of all 19 WNT genes have not been performed, there have been reports of overexpression of WNT2, WNT4, WNT5A, WNT7B, WNT10B, and WNT13 in a certain proportion of breast tumors [12,17-20]. Admittedly there are problems in interpreting such data, one of which is the difficulty in normalizing tissue RNA samples for variable epithelial/stromal contribution. In the case of WNT2, however, the relevant cell types have been investigated by in situ hybridization. With caveats regarding limited sample numbers, these studies imply that WNT2 is normally expressed only in stromal tissue of the breast, while in carcinomas it can be found in both the epithelium and the stroma [18]. The notion of a switch from a paracrine to an autocrine mechanism, making the tumor cells autonomous for Wnt signaling, is one that merits further evaluation.

\section{Mutation of the Wnt pathway: a paradigm in many human cancers}

Even in circumstances where there is clear overexpression of WNT genes in breast cancer, the case for their functional significance is difficult to prove in the absence of tumor-specific mutations or DNA rearrangements that activate WNT expression. Moreover, precedents from other signaling pathways would suggest that oncogenic mutations leading to constitutive signaling in cancer cells are more likely to be found in genes encoding receptors or downstream signaling components than in those encoding the ligands themselves. In recent years, the Wnt signaling pathway has become a paradigm of this principle.

A framework view of the canonical Wnt signaling pathway is shown in Figure 1. Cell surface receptors for Wnt proteins appear to be composed of at least two components: a seven transmembrane domain protein of the Frizzled family, and one of the low density lipoprotein receptorrelated proteins LRP5 or LRP6 [8,21-23]. Intracellular signaling proceeds via the proteins Axin and Dishevelled. A key downstream component of the pathway is $\beta$-catenin, a protein with dual functions in cell adhesion and transcriptional regulation. In the absence of Wnt signals, the cytosolic pool of $\beta$-catenin is continuously degraded as a result of its phosphorylation by glycogen synthase kinase$3 \beta$ (GSK-3 $\beta$ ) and subsequent ubiquitination. This phosphorylation occurs within a multi-protein complex that requires Axin and APC as participants. In response to Wnt signals, the ability of GSK-3 $\beta$ to phosphorylate $\beta$-catenin is inhibited. This leads to stabilization of $\beta$-catenin in the cytosol, and its subsequent translocation to the nucleus. Within the nucleus, $\beta$-catenin forms a complex with tran- 


\section{Figure 1}

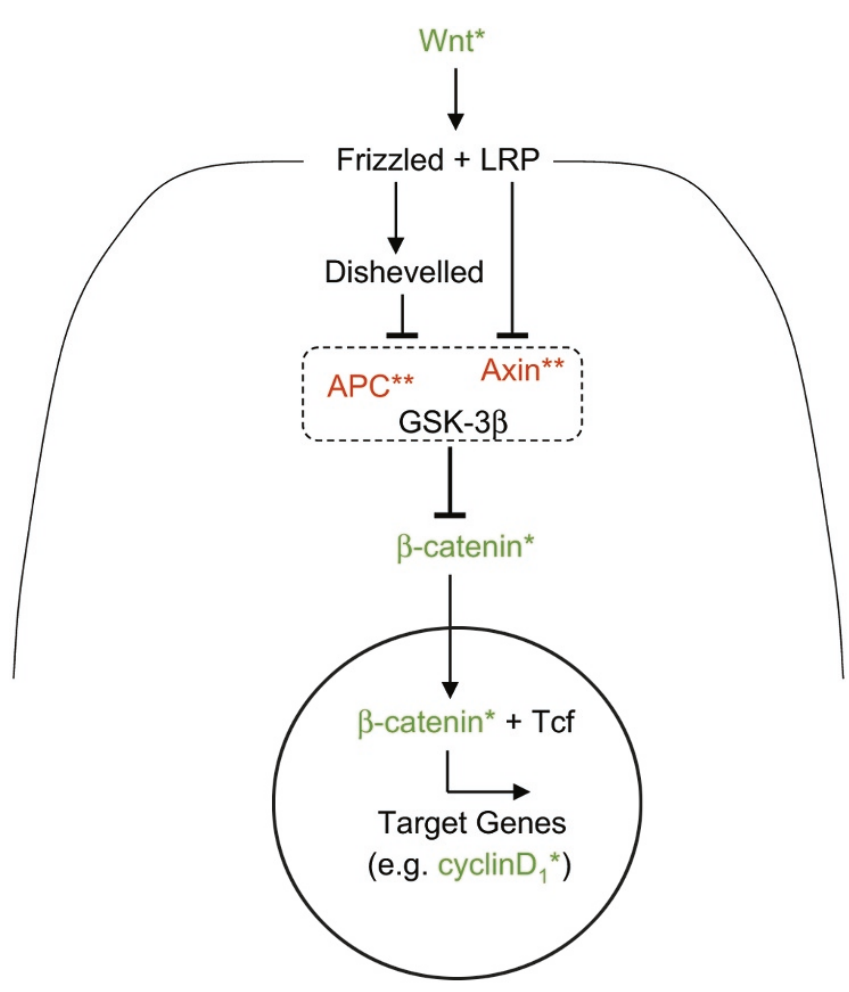

Simplified diagram of the canonical Wnt/ $\beta$-catenin signaling pathway. Wnt proteins bind to receptors thought to be composed of a Frizzled protein and either of the low density lipoprotein receptor-related proteins LRP5 or LRP6. Signaling via Dishevelled and/or Axin then results in inactivation of a multiprotein complex that normally renders $\beta$ catenin unstable. This complex (shown by a dotted rectangle) includes

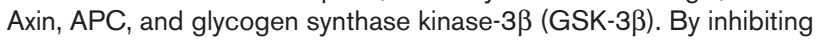
this complex, Wnt signals lead to accumulation of $\beta$-catenin in the cytosol and its entry into the nucleus. Once in the nucleus, $\beta$-catenin binds to proteins of the T-cell factor (Tcf)/lymphoid enhancer factor-1 (Lef1) family and modulates the expression of several target genes. * Components of the pathway identified as oncogenes in naturally occurring mouse or human cancers, ${ }^{* *}$ components identified as tumor suppressors.

scription factors of the T-cell factor (Tcf)/lymphoid enhancer factor-1 (Lef1) family and regulates expression of specific target genes. The precise targets may vary between cell types, but in some cases can include the oncogenes c-myc and cyclin $\mathrm{D}_{1}$ [21].

Several components of the Wnt signaling pathway have now been identified as oncogenes or tumor suppressors (showing gain-of-function or loss-of-function mutations, respectively) in human cancers, as shown in Figure 1. This is most evident in colon cancer, in which $85 \%$ of tumors have loss-of-function mutations in APC, an essential component of the machinery that destabilizes $\beta$-catenin [21]. As with continuous Wnt stimulation, APC mutations result in elevated $\beta$-catenin protein levels and subsequent $\beta$ catenin-Tcf transcriptional activity. Similar signaling conse- quences can result from mutational loss of $\mathrm{AXIN} 1$, as seen in hepatocellular carcinomas [24]. Oncogenic mutations in $\beta$-catenin itself, affecting the phosphorylation sites and resulting in a constitutively stable protein, have recently been detected in a remarkable variety of human cancers. These include colorectal tumors, medulloblastomas, hepatoblastomas, hepatocellular carcinomas, pilomatricomas, endometrial, prostatic, and thyroid carcinomas, and Wilms' tumors [21]. These data collectively imply that activation of the Wnt signaling pathway, by one means or another, is one of the most common signaling abnormalities known in human cancer.

\section{Evaluating the evidence in breast cancer}

In addition to the oncogenic effects of Wnt genes in mouse mammary cancer, there is further evidence that activation of the canonical Wnt signaling pathway promotes tumorigenesis in mouse mammary tissues. For example, certain mouse strains carrying a germline truncation mutation in Apc show enhanced sensitivity to carcinogen-induced mammary tumors [25], while transgenic animals expressing stabilized $\beta$-catenin in the mammary gland develop carcinomas [26]. In view of these observations in mouse models systems, together with the widespread occurrence of mutations that activate Wnt signaling in human cancers of other tissues, it is particularly surprising that equivalent mutations have generally not been detected in human breast cancers. Several laboratories have sought evidence for mutations in $\beta$-catenin, $A P C$, or $A X I N$ in breast cancer, as seen in other cancers, but few if any have been found [27-29]. The most numerous identified thus far are APC mutations reported in 18\% of breast cancers in a study using a yeast-based detection assay [30]. However, several of these mutations were located downstream of the cluster region for APC truncations associated with constitutive $\mathrm{Wnt} / \beta$-catenin signaling in colon cancer, and the status of the remaining APC allele in the tumors was uncertain [30]. Thus, where variants or mutations in Wnt pathway components have been found in breast cancer, it is not clear that they affect $\beta$-catenin levels or signaling $[30,31]$. In contrast, elevated $\beta$-catenin-Tcf transcriptional activity has been observed in certain breast cancer cell lines [32], and nuclear or cytoplasmic staining of $\beta$-catenin has been reported in as many as $60 \%$ of human breast cancer specimens in a recent study [32]. Most importantly, this staining pattern is an independent marker that correlates with poor prognosis [32].

In other tissues and other organisms, the appearance of $\beta$ catenin in the nucleus is typically considered to be a hallmark of activation of $\mathrm{Wnt} / \beta$-catenin signaling. How then can this be reconciled with the paucity of evidence for Wnt pathway mutations in breast cancer? There are several possible explanations. First, there might be tissuespecific use of functionally redundant proteins. For example, while Axin and APC are essential components of 
the $\beta$-catenin destruction machinery in the liver and colon, their homologs Conductin and APC2 might be the key players in human breast tissue. Mutational analysis of these genes in breast cancer has not yet been reported. Second, it is possible that, in breast cancer, Wnt signaling is activated by mutations in components of the pathway upstream of the Axin complex. Wnt receptors themselves could be candidate oncogenes in this context, and mutated forms of LRP5 and LRP6 have recently been shown to be capable of constitutive $\mathrm{Wnt} / \beta$-catenin signaling in cell culture $[22,23]$. It will be interesting to see whether comparable mutations are found in breast cancer. Mutational analysis of Frizzled genes may be more laborious because there are 10 different Frizzled family members, but there is a possible precedent for aberrant Frizzled expression contributing to cancer in another tissue. Frizzled7, which is not expressed in normal epithelium, was detected in $86 \%$ of poorly differentiated tumors in an analysis of esophageal cancer [33]. Wnt signaling in breast cancer might also be activated by other regulators of the pathway that have not yet been identified or analyzed. Since the number of proteins known to modulate $\mathrm{Wnt} / \beta$-catenin signaling either positively or negatively is growing rapidly [34], the list of candidate proto-oncogenes or tumor suppressors will continue to expand. Finally, it is of course possible that the pathway is not activated in a cell-autonomous manner by oncogenic mutations, but that excessive expression of Wnt ligands could account for the nuclear $\beta$-catenin staining seen in tumor biopsies and could contribute to tumor development in vivo. As already described, there is already preliminary evidence for WNT overexpression in a number of tumors.

\section{An Odyssey returns to its beginnings}

The pathway of discovery that has now re-opened questions about Wnt signaling in breast cancer is a remarkable one that has meandered among diverse fields of modern biology. From the initial identification of Wnt1 as an oncogene responsible for MMTV-induced tumors in mice came the surprising discovery that the homolog of Wnt1 in Drosophila is the segment polarity gene wingless [35]. Drosophila developmental genetics then produced a framework of the Wingless/Wnt signaling pathway, a key component of which was Armadillo [36]. Studies in Xenopus then revealed that Armadillo was homologous to the adherens junction protein $\beta$-catenin, that $\beta$-catenin could mediate Wnt signaling events and, remarkably, that it could enter the nucleus [37]. Jump now to hereditary colon cancer and the identification of APC as the tumor suppressor responsible for Familial Adenomatous Polyposis [38]. Studies of this novel protein soon showed that APC bound cytosolic $\beta$-catenin and facilitated its phosphorylation and destruction [39]. Oncogenic mutant forms of $\beta$-catenin were then discovered in colon cancer and many other cancers, and the detection of $\beta$-catenin in the nucleus was recognized as a characteristic feature of Wnt pathway activation [21]. Although specific fixation and staining methods may be required to reveal this in tissue sections, the recent immunohistochemical data of Lin et al [32] now bring this path back to breast cancer.

\section{Conclusion}

The relevance of Wnt1 to human breast cancer has been in question for nearly 20 years. A remarkable set of studies in Drosophila, Xenopus, mice, humans, and other species has now revealed a large family of Wnt proteins and a highly conserved pathway of intracellular signaling through which they act. Activation of this signaling pathway by mutation is a common feature of many human cancers. Few mutations of this sort have so far been described in breast cancer, but WNT proteins may be overexpressed in tumors and recent immunohistochemical evidence implies that components of the $\mathrm{Wnt} / \beta$-catenin pathway are activated in up to $60 \%$ of breast carcinomas [32]. Those who would describe a half-full glass as half-empty might argue that the case for Wnt signaling in breast cancer is not proven, but others would claim that the writing on the wall is writ large. It may be just a matter of time before we appreciate more clearly the mechanism and significance of Wnt pathway activation in breast cancer, in which case MMTV will have done its job and the connection between those early mouse models and human breast cancer will have come full circle.

\section{Acknowledgements}

Research on this topic in the author's laboratory is supported by the National Institutes of Health and by the US Army Breast Cancer Research Program. The author is grateful to L Howe, G Roberts, and K Brennan for comments on the manuscript.

\section{References}

1. Nusse R, Varmus HE: Many tumors induced by the mouse mammary tumor virus contain a provirus integrated in the same region of the host genome. Cell 1982, 31:99-109.

2. Bittner JJ: The milk influence of breast tumors in mice. Science 1942, 95:463.

3. Nusse R, Varmus HE: Wnt genes. Cell 1992, 69:1073-1087.

4. Tsukamoto AS, Grosschedl R, Guzman RC, Parslow T, Varmus $\mathrm{HE}$ : Expression of the int-1 gene in transgenic mice is associated with mammary gland hyperplasia and adenocarcinomas in male and female mice. Cell 1988, 55:619-625.

5. De Ome KB, Faulkin LJ, Bern HA: Development of mammary tumors from hyperplastic alveolar nodules transplanted into gland-free mammary fat pads of female $\mathrm{C} 3 \mathrm{H}$ mice. Cancer Res 1959, 19:515-520.

6. Nusse R: Insertional mutagenesis in mouse mammary tumorigenesis. Curr Topics Microbiol Immunol 1991, 171:43-66.

7. Van de Vijver MJ, Nusse R: The molecular biology of breast cancer. Biochim Biophys Acta Rev Cancer 1991, 1072:33-50.

8. Cadigan KM, Nusse R: Wnt signaling: a common theme in animal development. Genes Dev 1997, 11:3286-3305.

9. Herzlinger D, Qiao J, Cohen D, Ramakrishna NR, Brown AMC: Induction of kidney epithelial morphogenesis by cells expressing Wnt-1. Dev Biol 1994, 166:815-819.

10. Kispert A, Vainio S, McMahon AP: Wnt-4 is a mesenchymal signal for epithelial transformation of metanephric mesenchyme in the developing kidney. Development 1998, 125: 4225-4234.

11. Shimizu H, Julius MA, Zheng Z, Giarre M, Brown AMC, Kitajewski $\mathrm{J}$ : Mammary cell transformation by Wnt family proteins correlates with regulation of beta-catenin. Cell Growth Differ 1997, 8:1349-1358. 
12. Bergstein I, Brown AMC: WNT genes and breast cancer. In Breast Cancer: Molecular Genetics, Pathogenesis and Therapeutics. Edited by Bowcock AM. Totowa, NJ: Humana Press Inc.; 1999:181-198.

13. Lane TF, Leder P: Wnt-10b directs hypermorphic development and transformation in mammary glands of male and female mice. Oncogene 1997, 15:2133-2144.

14. Gavin BJ, McMahon JA, McMahon AP: Expression of multiple novel Wnt-1/int-1-related genes during fetal and adult mouse development. Genes Dev 1990, 4:2319-2332.

15. Weber-Hall SJ, Phippard DJ, Niemeyer CC, Dale TC: Developmental and hormonal regulation of Wnt gene expression in the mouse mammary gland. Differentiation 1994, 57:205214.

16. Brisken C, Heineman A, Chavarria T, Elenbaas B, Tan J, Dey SK, McMahon JA, McMahon AP, Weinberg RA: Essential function of Wnt-4 in mammary gland development downstream of progesterone signaling. Genes Dev 2000, 14:650-654.

17. Huguet EL, McMahon JA, McMahon AP, Bicknell R, Harris AL: Differential expression of human Wnt genes 2, 3, 4, and 7B in human breast cell lines and normal and diseased breast tissue. Cancer Res 1994, 54:2615-2621.

18. Dale TC, Weber-Hall SJ, Smith $K$, Huguet EL, Jayatliake $H$, Gusterson BA, Shuttleworth G, O'Hare M, Harris AL: Compartment switching of WNT-2 expression in human breast tumors. Cell Regulat 1996, 56:4320-4323.

19. Lejeune S, Huguet EL, Hamby A, Poulsom R, Harris AL: Wnt5a cloning, expression, and up-regulation in human primary breast cancers. Clin Cancer Res 1995, 1:215-222.

20. Bui TD, Rankin J, Smith K, Huguet EL, Ruben S, Strachan T, Harris AL, Lindsay S: A novel human Wnt gene, WNT10B, maps to $12 \mathrm{q} 13$ and is expressed in human breast carcinomas. Oncogene 1997, 14:1249-1253.

21. Polakis P: Wnt signaling and cancer. Genes Dev 2000, 14: 1837-1851.

22. Mao J, Wang J, Liu B, Pan W, Farr GH 3rd, Flynn C, Yuan H, Takada S, Kimelman D, Li L, Wu D: Low-density lipoprotein receptor-related protein-5 binds to Axin and regulates the canonical Wnt signaling pathway. Mol Cell 2001, 7:801-809.

23. Mao B, Wu W, Li Y, Hoppe D, Stannek P, Glinka A, Niehrs C: LDL-receptor-related protein 6 is a receptor for Dickkopf proteins. Nature 2001, 411:321-325.

24. Satoh S, Daigo Y, Furukawa Y, Kato T, Miwa N, Nishiwaki T, Kawasoe T, Ishiguro H, Fujita M, Tokino T, Sasaki Y, Imaoka S, Murata M, Shimano T, Yamaoka Y, Nakamura Y: AXIN1 mutations in hepatocellular carcinomas, and growth suppression in cancer cells by virus-mediated transfer of AXIN1. Nat Genet 2000, 24:245-250.

25. Moser AR, Hegge LF, Cardiff RD: Genetic background affects susceptibility to mammary hyperplasias and carcinomas in Apc(min)/+ mice. Cancer Res 2001, 61:3480-3485.

26. Imbert A, Eelkema R, Jordan S, Feiner H, Cowin P: $\Delta$ N89 $\beta$ catenin induces precocious development, differentiation, and neoplasia in mammary gland. J Cell Biol 2001, 153:555-568.

27. Candidus $S$, Bischoff $P$, Becker KF, Hofler $H$ : No evidence for mutations in the alpha- and beta-catenin genes in human gastric and breast carcinomas. Cancer Res 1996, 56:49-52.

28. Schlosshauer PW, Brown SA, Eisinger K, Yan Q, Guglielminetti ER, Parsons R, Ellenson LH, Kitajewski J: APC truncation and increased beta-catenin levels in a human breast cancer cell line. Carcinogenesis 2000, 21:1453-1456.

29. Jonsson M, Borg A, Nilbert M, Andersson T: Involvement of adenomatous polyposis coli (APC)/beta-catenin signalling in human breast cancer. Eur J Cancer 2000, 36:242-248.

30. Furuuchi K, Tada M, Yamada H, Kataoka A, Furuuchi N, Hamada J, Takahashi M, Todo S, Moriuchi T: Somatic mutations of the APC gene in primary breast cancers. Am J Pathol 2000, 156:19972005.

31. Webster MT, Rozycka M, Sara E, Davis E, Smalley M, Young N, Dale TC, Wooster R: Sequence variants of the axin gene in breast, colon, and other cancers: an analysis of mutations that interfere with GSK3 binding. Genes Chromosomes Cancer 2000, 28:443-453.

32. Lin SY, Xia W, Wang JC, Kwong KY, Spohn B, Wen Y, Pestell RG, Hung MC: Beta-catenin, a novel prognostic marker for breast cancer: its roles in cyclin D1 expression and cancer progression. Proc Natl Acad Sci USA 2000, 97:4262-4266.
33. Tanaka S, Akiyoshi T, Mori M, Wands JR, Sugimachi K: A novel frizzled gene identified in human esophageal carcinoma mediates APC/beta-catenin signals. Proc Natl Acad Sci USA 1998, 85:10164-10169.

34. Martinez Arias A, Brown AMC, Brennan K: Wnt signalling: pathway or network? Curr Opin Genet Dev 1999, 9:447-454

35. Rijsewijk F, Schuerman M, Wagenaar E, Parren P, Weigel D, Nusse R: The Drosophila homolog of the mouse mammary oncogene int-1 is identical to the segment polarity gene wingless. Cell 1987, 50:649-657.

36. Riggleman B, Schedl P, Wieschaus E: Spatial expression of the Drosophila segment polarity gene armadillo is posttranscriptionally regulated by wingless. Cell 1990, 63:549-560.

37. Funayama N, Fagotto F, McCrea P, Gumbiner B: Embryonic axis induction by the armadillo repeat domain of beta-catenin: evidence for intercellular signaling. J Cell Biol 1995, 128:959968.

38. Kinzler KW, Vogelstein B: Lessons from hereditary colorectal cancer. Cell 1996, 87:159-170.

39. Munemitsu S, Albert I, Souza B, Rubinfeld B, Polakis P: Regulation of intracellular beta-catenin levels by adenomatous polyposis coli (APC) tumor-suppressor protein. Proc Natl Acad Sci USA 1995, 92:3046-3050. 